TITLE:

\title{
Estimation of Lifeline Resilience Factors Based on Surveys of Japanese Industries
}

$\operatorname{AUTHOR}(S)$ :

Kajitani, Yoshio; Tatano, Hirokazu

\section{CITATION:}

Kajitani, Yoshio ... [et al]. Estimation of Lifeline Resilience Factors Based on Surveys of Japanese Industries. Earthquake Spectra 2009, 25(4): 755-776

ISSUE DATE:

2009-11

URL:

http://hdl.handle.net/2433/240968

\section{RIGHT:}

Copyright 2009 Earthquake Engineering Research Institute. This article may be downloaded for personal use only. Any other use requires prior permission of the Earthquake Engineering Research Institute.; この論文は出版社版でありませ ん。引用の際には出版社版をご確認じ利用ください。; This is not the published version. Please cite only the published version. 


\section{Title: Estimation of Lifeline Resiliency Factors Based on Surveys of Japanese Industries}

Authors: Yoshio Kajitani and Hirokazu Tatano

This is an Accepted Manuscript of an article "Yoshio Kajitani and Hirokazu Tatano (2009) Estimation of Lifeline Resilience Factors Based on Surveys of Japanese Industries. Earthquake Spectra: November 2009, Vol. 25, No. 4, pp. 755-776. https://doi.org/10.1193/1.3240354".

Copyright $(\mathcal{2} 2009$ Earthquake Engineering Research Institute. This article may be downloaded for personal use only. Any other use requires prior permission of the Earthquake Engineering Research Institute. 


\title{
Estimation of Lifeline Resiliency Factors Based on Surveys of Japanese Industries
}

\author{
Yoshio Kajitania) and Hirokazu Tatano ${ }^{\text {b) }}$
}

This paper discusses the resiliency factors of industrial sectors under lifeline (electricity, water, and gas) system disruptions. The resiliency factor is one of the quantitative measurements of lifeline impacts, which focuses on the production output of some industrial sectors during lifeline disruptions. Recent studies have provided the detailed structure of business resilience that includes multiple resiliency options such as production rescheduling, inventories, back-up generators, etc. However, the impacts of these options on resiliency factor are not thoroughly investigated due to the lack of data. In addition, resiliency factor in previous study is assumed to be applied only to the single-lifeline disruption case, which is a limited case in large-scale disasters.

In this study, the resiliency factors for 27 industrial sectors are estimated based on the empirical surveys conducted in the Aichi and Shizuoka Prefectures, Japan,

\footnotetext{
a) Central Research Institute of Electric Power Industry, 1646 Abiko, Abiko City, Chiba 2701194, Japan

b) Disaster Prevention Research Institute, Kyoto University, Gokasyo, Uji, Kyoto 6110011, Japan
} 
focusing on more rigorous characteristics of resilience. One particular contribution of this paper is introducing the resiliency factor that considers individual and compound effects of available resiliency options along with multiple lifeline disruptions.

\section{INTRODUCTION}

As the majority of the population and businesses are concentrated in cities, lifeline systems are becoming increasingly more important in supporting our lives and business activities. Accordingly, we must consider countermeasures to reduce the risk of lifeline system failures induced by natural disasters, operational errors, etc. In order to facilitate costeffective countermeasures for such occurrences, quantitative measurements are required.

Impacts of lifeline disruptions vary among different business sectors, mainly because of the differences in production mechanisms that use critical lifeline resources in differing amounts. Therefore, many outage cost surveys of different industrial or household sectors have been conducted in many countries. The resiliency factor is one of the quantitative measurements of lifeline impacts, which focuses on the production output of some industrial sectors during an arbitrary period of lifeline disruptions. This indicator has played an important role in the models developed for estimating economic losses caused by disruption of public utilities.

Originally, the resiliency factor was estimated in terms of the production level in percentage terms that is sustainable without any reliance on lifeline supply, such as that given in ATC-13 and ATC-25 (originally referred to as the importance factor). Most studies today 
consider importance factor as a single resilience option, rather than as a general heading for resilience that includes multiple options such as production rescheduling, inventories, backup generators, etc. The idea of resilience must be extended to consider its more essential structure and components.

For example, Bruneau et al. (2003) proposed a conceptual framework for community resilience, which is classified by four dimensions (technical, organizational, social, and economic); each resiliency factor is characterized by four properties (robustness, rapidity, redundancy, and resourcefulness). Chang and Shinozuka (2004) focused on robustness and rapidity and proposed a method to measure technical and economic resiliencies. In terms of economic resilience, Rose and Liao (2005) used a computable general equilibrium framework to incorporate several components of resilience such as substitution of inputs, conservation, and price mechanisms (market mechanisms for reallocating scarce resources). Thus, structures of resilience and measurement techniques for individual business and regional economies have been advanced both conceptually and empirically.

However, no matter how precisely the structure of resiliency is determined, it is difficult to implement these ideas in estimation of economic losses because of lack of data. ATC-13 (1985) and ATC-25 (1991) are pioneering works that demonstrate resiliency factors, but these values reflect a limited aspect of resiliency and are determined based on expert opinion that is limited. In addition, empirical business survey results on economic impacts of lifeline disruptions, such as the ones conducted in Shelby County, Tennessee and Los Angeles, California in the United States (Tierney, 1997), have been utilized for estimating resiliency factors. However, it is reported that resiliency factors based on the empirical values are inconsistent across different surveys (Chang et al., 2002). The less structured resiliency 
factors used in empirical surveys may cause this inconsistency, and therefore, continuous empirical surveys and an investigation of survey methodology are required ${ }^{1}$.

In Japan, databases related to the resiliency factor of business have been accumulated (e.g., Kajitani et al. 2004, 2005). Surveys pertaining to these databases were conducted in Aichi and Shizuoka Prefectures. Originally, this database was intended to obtain the resiliency factor similar to how the ATC-13 led to the importance factor. It is characteristic that production levels are estimated for all possible supply-type lifeline ${ }^{2}$ disruptions (i.e., electricity, water, and gas). Because lifeline disruption and recovery patterns may change over space and time, it is important to estimate the resiliency under different lifeline disruption patterns.

This database also includes important items related to business resiliency, which have not been thoroughly investigated and quantified in previous research. These are related to effects of resiliency options such as backup systems, inventories, production rescheduling, etc ${ }^{3}$. One particular contribution of this paper is introducing the resiliency factor that considers individual and compound effects of available resiliency options along with multiple lifeline disruptions. This is helpful not only for estimating the more sensitive economic impacts of lifeline disruptions, but is also beneficial for the management and the disaster prevention

\footnotetext{
${ }^{1}$ There are some reasons, other than the variety of resiliency options, due to which the empirical survey results can be inconsistent. For example, sample sizes, survey forms, and the manner in which the question have been worded, such as the expression of disaster situation can significantly affect the survey results.

${ }^{2}$ Supply-type lifeline is defined as the infrastructure delivering the resources to users. Similarly, there can be other groupings such as transportation-type lifeline (road and railway), communication-type lifeline (telephone and internet), etc. In the present context of a disruption scenario, essential infrastructure has been regarded as lifeline.

${ }^{3}$ Resiliency options are regarded as the measures that help reduce the business interruption loss after the physical damages occur to structures. The idea does not include mitigation measures, which directly reduce physical damages.
} 
departments in the local and central governments with regard to the introduction of effective resiliency options.

An outline of subsequent sectors in this paper is as follows. In Section 2, measurement of resiliency factor in this study is defined based on previous research on business resiliency. Following this, the survey methodologies for the database essential for estimation of the resiliency factor are reviewed and the mathematical form of the resiliency factor based on the surveyed data is expressed. In Section 3, sample characteristics and estimation results of resiliency factor are discussed comparing with ATC-13 resiliency factors for single-lifeline disruptions. In Section 4, resiliency factors that take into multiple lifeline disruptions and multiple resiliency options are estimated. For estimating the resiliency factor in a specific lifeline disruption scenario, we consider the estimated lifeline disruption duration during the Tokai Earthquake as a case study.

\section{MEASUREMENTS OF BUSINESS RESILIENCY UNDER LIFELINE DISRUPTIONS IN THIS STUDY}

\section{BASIC CONCEPTS}

The basic concept of business resiliency is the ability to reduce losses under external unpredictable disturbances such as natural disasters. The detailed factors of resiliency are various, and have been pointed out and measured by previous researchers. For example, Rose and Liao (2005) propose factors of resilience such as conservation and substitution. In their research, some of these components are expressed in the coefficient of production function; however, the estimation of all the factors affecting resiliency is difficult because of lack of data. Rose et al. (2007) focused on electricity outage, and measured several effects of resiliency factors: adaptive electricity substitution, electricity conservation, electricity 
importance, alternative generation, production rescheduling. In the case study of a two week power outage in Los Angeles, it was found that production rescheduling is the most effective resiliency option, followed by electricity importance and alternative generation.

Comparing the many researches on the topic of measurement of resiliency factors, our study focuses on the basic part of resiliency factors. This study does not cover macroeconomic resiliency-the price mechanism ensures effective resource allocation; on the contrary, resiliency is estimated on an individual basis. First, we measure the lifeline importance factor as given in ATC-13 (1985). Note that our main focus is to estimate sectoral production levels under multiple lifeline disruptions. This is an enhancement of ATC-13 and is important for estimating the effect of different lifeline recovery patterns on dynamically changing production levels. In our study, the proportion of production level under lifeline system disruptions to the normal production level is estimated as a resiliency factor. Figure 1 demonstrates the resiliency factor reflecting only lifeline importance under such disruptions. It is assumed that other facilities have not been damaged and the speed of recovery following the restoration of lifeline supply is rapid. Production levels under different patterns of lifeline disruptions $\left(2^{3}=8\right.$ patterns $)$ are estimated based on questionnaire surveys. The value is determined after the amount of lifeline usage for individual production machines and business operations was carefully examined and answered by each business. Based on these data sets, the benefit of a specific lifeline recovery program under the different supply statuses of the other two lifelines can also be estimated. 


\section{Production}

level

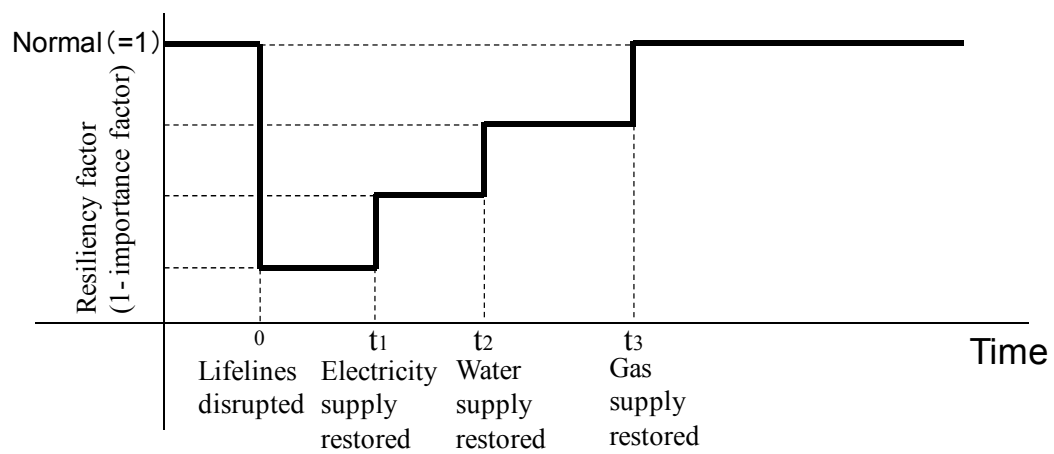

Figure 1. Conceptual figure of impacts of simultaneous supply-type lifeline disruptions and their recoveries

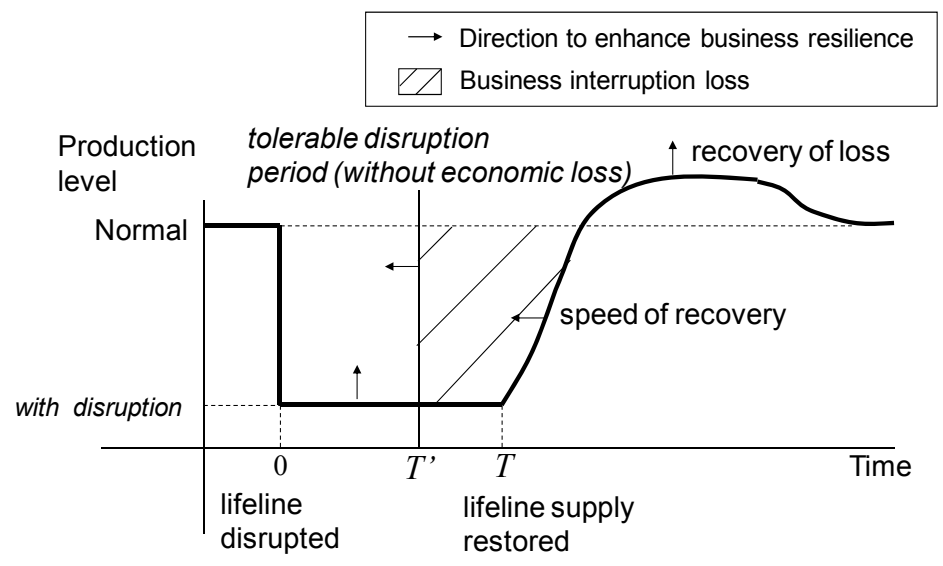

Figure 2. Business Interruption Loss and Business Resilience

In general, damage and recovery pattern of business under lifeline disruption can be depicted as is shown in Figure 2. For simplicity, the lifelines are considered to have recovered simultaneously. Business interruption loss is determined by three options of resilience: production level under lifeline disruptions, speed of recovery, and recovery of loss after restarting work. In Chang and Shinozuka (2004), production level under lifeline disruptions and speed of recovery correspond to "robustness" and "rapidity," respectively. 
In addition to these two aspects, it is important to consider recovery of (temporary) loss after restarting work. That is, temporal interruption of business transactions can be recovered during the following days by rotating shifts, adjusting production schedules with business partners or customers, etc.

The production reschedule can last for a long period in accordance with the flexibility of demand. Rose and Lim (2002) pointed out that this kind of production rescheduling at a later date is effective in enhancing business resilience; Rose and Lim (2002) also adopted the loss estimation manual in HAZUS as a recapture factor. This study focuses on only for a shortterm recuperating of loss. That is, business loss is determined by whether or not a cancellation of either present or already accepted demands occurs. The current study focuses on only short-term recuperation of loss.

To find the effects of recovery of loss by production rescheduling, this study focuses on the tolerable disruption period. In addition to flexibility of production rescheduling, this measurement reflects the compound effects of speed of recovery and amount of inventories required to maintain service during lifeline disruption. In our study, answers to tolerable production stoppage periods are investigated after obtaining the average inventory levels, daily production system usage, and the duration time between the receipt of an order and the final delivery to the customer. When we determine the tolerable disruption period, the revealed business interruption loss at time $(T)$ when lifeline system is recovered is assumed to be the production or services that cannot be achieved and/or recovered in the future; this is shown in Figure 2.

In this way, our study mainly focuses on two resiliency characteristics; production level under lifeline disruptions (reflecting only lifeline importance) and tolerable production (lifeline) stoppage periods. These resiliency measurements are basically static, but can be 
applied to different disruption patterns, which are dynamic and change according to the recovery activities ${ }^{4}$. In addition, this study intends to estimate the effects of several resiliency options, with particular focus on back-up, substitution, and storage of each lifeline.

\section{QUESTIONNAIRE DESIGN FOR AICHI-SHIZUOKA REGION, JAPAN}

Figure 3 shows a map of Japan and the prefectures where surveys for estimating resiliency factors under lifeline disruptions were conducted. There is a high probability that a scenario referred to as the "Tokai Earthquake" will occur in this area in the near future, but not many industries are expected to experience long-term lifeline disruptions.

Samples are divided into two categories; manufacturing sectors and non-manufacturing sectors, and surveys are conducted in two different periods. These two categories have the largest difference in amount of lifeline usages and purposes of lifeline uses; for example, raw material usage in manufacturing sector is much higher. This sectoral contrast is expected to produce the largest difference of impacts under lifeline disruptions. However, key questions used in our surveys to estimate resiliency factor are basically identical for both sectors; the common key questions are shown in Appendix A.

Survey forms were sent to individual firms which were randomly singled out from a telephone address database. A total of 1080 businesses (725 manufacturing and 355 nonmanufacturing sectors) were surveyed; survey forms for manufacturing and nonmanufacturing sectors differed slightly. The survey form in non-manufacturing sector

\footnotetext{
4 According to Rose (2004), economic resilience can be defined statically and dynamically. Static economic resilience refers to the ability of capacity of a system to absorb or cushion the damage or loss. Dynamic economic resilience is the ability of a system to recover from a severe shock. To estimate the dynamic resiliency factor, it is important to estimate the recovery line at any time.
} 
contains an extra question regarding the estimations of resiliency factors "with" and "without" the countermeasures such as back-up power generators. This extra question is intended to more clearly evaluate the effect of countermeasures considering the limited number of non-manufacturing businesses who have countermeasures.

The main characteristic of these two surveys is the consideration of multiple lifelines. That is, production levels are estimated under eight different disruption patterns for three supply-type lifelines ( $2^{3}$ factorial design). Production levels are estimated as $0,0.25,0.50$, $0.75,1$ or any appropriate number the company can suggest. Table 1 provides summary information on the surveys.

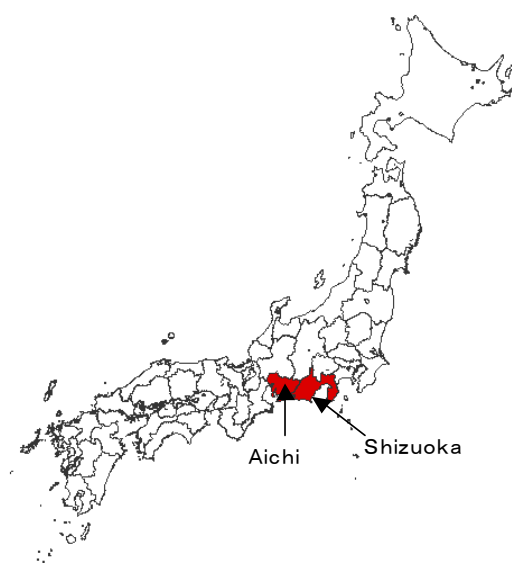

Figure 3. Aichi and Shizuoka Prefectures

Table 1. Surveys of Resiliency Factors in Japan

\begin{tabular}{|l|l|l|l|}
\hline Area & Period & Sample-Sizes & Survey Outlines \\
\hline $\begin{array}{l}\text { Aichi and } \\
\text { Shizuoka }\end{array}$ & $2003 / 09 / 20-$ & $\begin{array}{l}725 \text { manufacturing } \\
\text { businesses } \\
\text { (Response rate } \\
18.12 \%)\end{array}$ & $\begin{array}{l}\text { Multiple supply-type lifeline disruptions (See } \\
\text { Figure 1), tolerable production stop period } \\
\text { (See Figure 2) }\end{array}$ \\
\hline $\begin{array}{l}\text { Aichi and } \\
\text { Shizuoka }\end{array}$ & $\begin{array}{c}2004 / 08 / 01- \\
2004 / 08 / 31\end{array}$ & $\begin{array}{l}355 \text { non-manufacturing } \\
\text { businesses } \\
\text { (Response rate = 11.8\%) }\end{array}$ & $\begin{array}{l}\text { Multiple supply-type lifeline disruptions and } \\
\text { effect of back-up systems and alternative } \\
\text { resources, tolerable production stop period }\end{array}$ \\
\hline
\end{tabular}




\section{ESTIMATION MODEL OF RESILIENCE FACTOR IN THIS STUDY}

Consistent measurements for the resiliency factors given in Figures 2 and 3 are defined in this section. First, the production level of a business $j$ in sector $i$ at a certain time is assumed to be stable and is defined as $P_{i}^{j}(\mathbf{L}, \mathbf{O})$. Here, production level is defined such that business $j$ can get output $P_{i}^{j}(\mathbf{L}, \mathbf{O}) \times S$ if the business activity maintains the same production level for period $S$. Index $\mathbf{L}$ is a vector of the supply status of lifelines. $\mathbf{O}$ is the vector denoting the status (active/inactive) of each resiliency option. We take two values for each option of the two options-backup systems and alternative resources-in our study; 1: the option is active and 0 : the option is not active. Other production-related factors, such as labor and production facilities, are assumed to be constant. Change of demand during disasters is also assumed to be identical before and after the lifeline disruptions.

Firstly, we consider the resiliency factor in the case of Figure 1. Let us respectively define $\mathbf{L}_{t}^{\prime}$ and $\mathbf{O}_{t}^{\prime}$ as the lifeline supply status and resiliency option status under a disaster situation at time $t$ and assume $\mathbf{L}_{t}^{\prime}=\mathbf{L}^{\prime}$ and $\mathbf{O}_{t}^{\prime}=\mathbf{O}^{\prime}$ during period $0<t \leq T$, where 0 indicates the disruption time of lifeline systems and $\mathrm{T}$ indicates the recovery time of all the lifeline systems. Then, the resiliency factor, which is the standardized production level at time $t$, is given as follows:

$$
R F_{i}^{j}\left(\mathbf{L}^{\prime}, \mathbf{O}^{\prime}\right)=\frac{P_{i}^{j}\left(\mathbf{L}^{\prime}, \mathbf{O}^{\prime}\right)}{P_{i}^{j}(\mathbf{L}, \mathbf{O})}
$$

where $P_{i}^{j}\left(\mathbf{L}^{\prime}, \mathbf{O}^{\prime}\right) / P_{i}^{j}(\mathbf{L}, \mathbf{O})$ is provided by each firm based on the questionnaire form in Appendix A. As we discussed in the previous section, each firm surveyed in the manufacturing sector provided the value only when the resiliency options if they are available 
are used, while each firm in the non-manufacturing sector provided the values both when the resiliency options are used and not used.

In general, because lifeline recovery patterns and options' status can be many and change over time, the resiliency factor for disruption period $T$ can be calculated as follows:

$$
R F_{i}^{j}\left(\mathbf{L}_{t}^{\prime}, \mathbf{O}_{t}^{\prime} \mid 0<t \leq T\right)=\frac{1}{T} \int_{0}^{T} \frac{P_{i}^{j}\left(\mathbf{L}_{t}^{\prime}, \mathbf{O}_{t}^{\prime}\right)}{P_{i}^{j}(\mathbf{L}, \mathbf{O})} d t
$$

In our estimate, the average resiliency factor for businesses in sector $i$ is adopted and calculated as follows:

$$
R F_{i}\left(\mathbf{L}_{t}^{\prime}, \mathbf{O}_{t}^{\prime} \mid 0<t \leq T\right)=\frac{1}{n} \sum_{j=1}^{n} R F_{i}^{j}\left(\mathbf{L}_{t}^{\prime}, \mathbf{O}_{t}^{\prime} \mid 0<t \leq T\right)
$$

Next, we define the resiliency factor in the case of Figure 2. If the recovery speed of production level and the recovery of temporary production losses, which is produced after the lifeline systems, are restored and are accounted for as shown in Figure 2, resiliency factor, which is redefined using the tolerable duration of production stop $T^{\prime}$ 'is as follows:

$$
R F_{i}^{j}\left(\mathbf{L}_{t}^{\prime}, \mathbf{O}_{t}^{\prime} \mid 0<t \leq T\right)= \begin{cases}1 & \text { if } T \leq T^{\prime} \\ \frac{1}{T}\left(\int_{0}^{T-T^{\prime}} \frac{P_{i}^{j}\left(\mathbf{L}_{t}^{\prime}, \mathbf{O}_{t}^{\prime}\right)}{P_{i}^{j}(\mathbf{L}, \mathbf{O})} d t+T^{\prime}\right) & \text { if } T>T^{\prime} .\end{cases}
$$

In actuality, $T^{\prime}$ can take various values depending on the various production levels determined by the different patterns of lifeline disruptions. In our survey, replies are obtained for only one case-production ceases completely when systems are disrupted (Appendix A). This is the severest case in the sense that the temporary losses to be recovered are largest, and hence, the estimation of the resiliency factor, when our survey data is used, tends to be the smallest. In addition, costs for extra inputs are not considered in our study. Usually, extra costs, such as the costs for extending working hours, are required to ensure recovery of 
production, and it is necessary to consider these costs while assessing resiliency option in order to estimate the total losses caused by lifeline disruptions.

\section{ESTIMATION OF RESILIENCY FACTOR (IMPORTANCE FACTOR) UNDER ELECTRICITY, WATER, AND GAS DISRUPTION}

\section{SAMPLE CHARACTERISTICS}

The resiliency factor in this paper is based on the answers given by businesses. Therefore, the contents of the questionnaire are carefully determined because each question on sample characteristics helps the targeted businesses in easily picturing and estimating their production conditions under various lifeline disruptions.

In our analysis, resiliency factors are estimated for 27 different sectors and the attributes of each sector are carefully checked. However, this paper has presented a rough summary of each attribute due to space limitations. A detailed analysis of the sample characteristics can be found in previous papers-Kajitani et al. $(2004,2005)$.

Figures 4 and 5 show the sources of water and gas. The non-manufacturing sector depends more on the city water and gas utilities than the manufacturing sector. In other words, the introduction rate of underground water and propane gas is high in the manufacturing sector, which increases the resiliency toward water and gas disruptions. However, in both the manufacturing and non-manufacturing sectors, the percentage of electricity from independent power generators for personal business use (different from that of power system companies) is less than $5 \%$ of the total usage. 


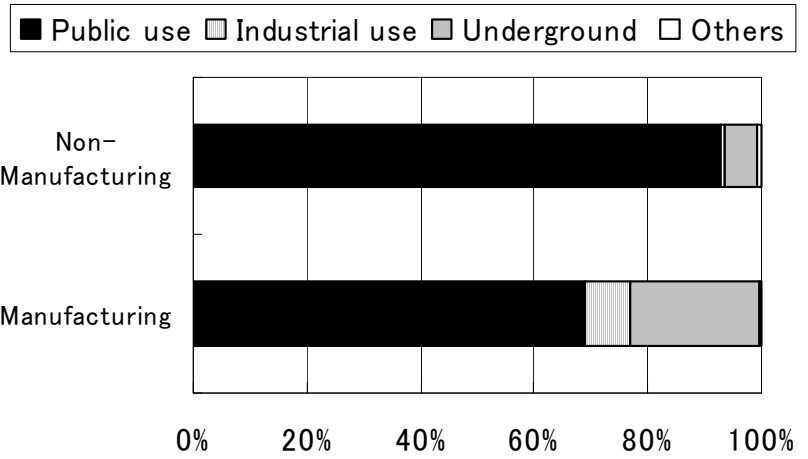

Figure 4. Sources of water (percent of sample; effective samples: $\mathrm{N}=711$ manufacturing and $\mathrm{N}=355$ non-manufacturing firms)

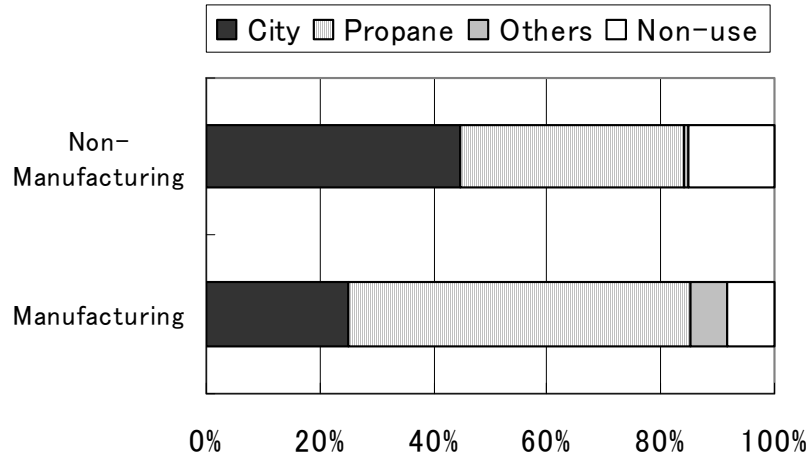

Figure 5. Sources of gas (percent of sample; effective samples: $N=711$ manufacturing and $N=355$ non-manufacturing firms)

On the other hand, the individual purpose of the usage of each lifeline is also important for estimating the production levels under lifeline disruptions. Figures 6 and 7 show the number of sample proportions, classified by each purpose of lifeline use. Proportion of businesses using electricity for production is the largest in the manufacturing sector. Proportion of samples using electricity for computing is also large in the manufacturing sector, but not as large as the proportion in the non-manufacturing sector. Depending on the development of information technology in recent years, these proportions are expected to change henceforth. 
Except for washrooms and kitchens, water is mainly used for cooling or as a raw material in manufacturing sector; this however is not the case in the non-manufacturing sector. In both sectors, gas is mainly used in kitchens. Though not shown in the figure, 76 businesses in the manufacturing sector have installed production equipment that utilizes all three lifelines.

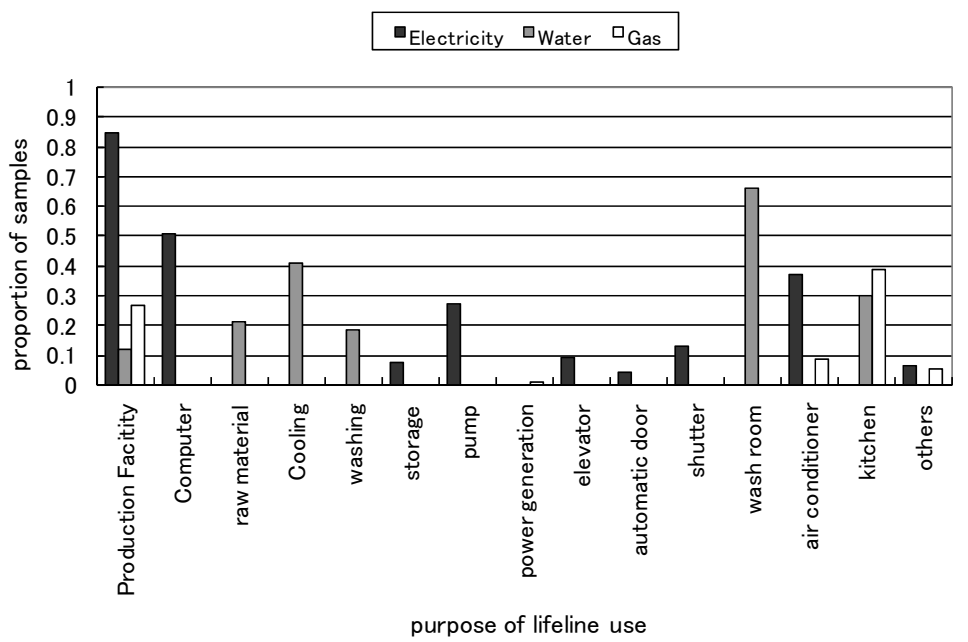

Figure 6. Proportion of businesses using electricity for various purposes in the manufacturing sector $(\mathrm{N}=711$ samples $)$

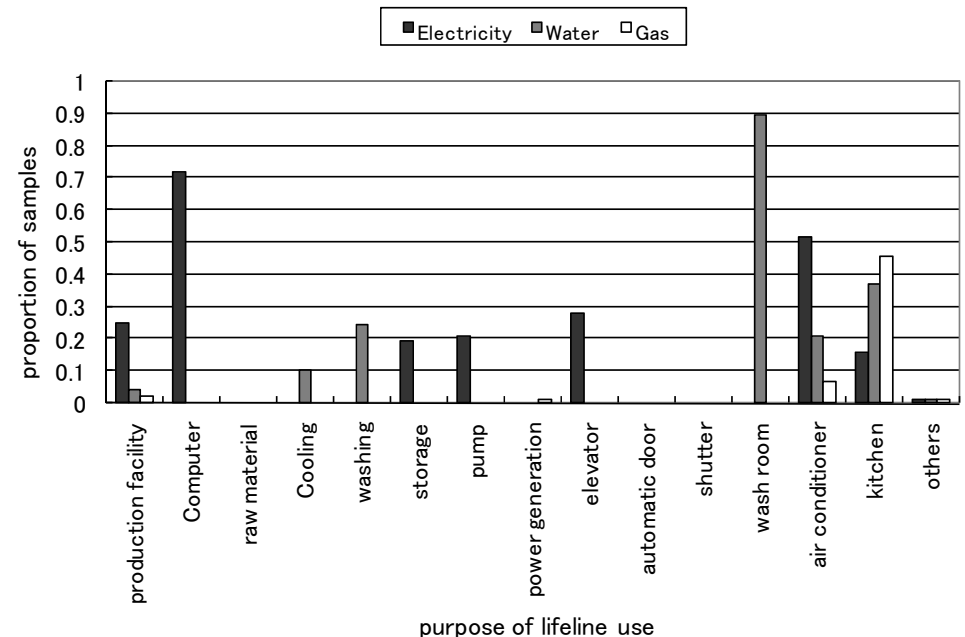

Figure 7. Proportion of businesses using electricity for various purposes in the non-manufacturing sector $(\mathrm{N}=355$ samples) 


\section{ESTIMATED RESILIENCY FACTOR FOR 27 INDUSTRIAL SECTORS UNDER INDIVIDUAL LIFELINE DISRUPTION}

Based on Equation (3), the resiliency factors for 15 manufacturing and 12 nonmanufacturing sectors are estimated and presented in Tables 2 and 3, respectively. All the samples are equally weighted regardless of the business size ${ }^{5}$. Electricity disruption is assumed to occur only in the regional power grid. The smaller, independent generators supplying power for personal business use are assumed to be perfect. Similarly, water disruption occurs only in the regional water supply system. Gas disruption indicates disruption in the city's gas grid. In both manufacturing and non-manufacturing sectors, resiliency options such as underground water are accounted for and reflected in the values of resiliency factors ${ }^{6}$.

Within the manufacturing sector, most businesses have to completely stop production when there are disruptions in electricity supply. The refinery \& coal sector has the largest resiliency $(\mathrm{RF}=0.15)$. Only one of the 18 firms in the refinery sector stated that they had their own power generators. However, it is known that the refinery sector can use gas and oil produced during the refining process for power generation. Some of the samples do reflect this characteristic without mentioning any back-up or the daily usage of power generation. On the other hand, the non-manufacturing sectors are more resilient to electricity disruption

\footnotetext{
${ }^{5}$ Resiliency factors classified by output levels do not produce any meaningful relationships with the exception of water disruption. In water disruption, resiliency factor monotonically decreases as the output level increases in the manufacturing sector (e.g. 0.64 (0-100 million yen), 0.58 (100-1000), $0.49(1000+))$. This result indicates that large businesses may suffer more when it comes to maintaining the number of employees, delivering water from other sources, etc. This is against the expectation that a large company has more resources to invest in resiliency options; it is necessary to observe more samples to verify this tendency.
} 
(average $\mathrm{RF}=0.37$ ). As can be imagined, some operations, such as retailing and logistics, do not depend quite as much on electricity. However, as modern businesses depend more on information technology, such as intra- and inter-nets, there is a possibility that the resiliency factor in the non-manufacturing sector decreases.

Average resiliency factors for water and gas disruptions are comparable between manufacturing and non-manufacturing industries. Focusing on more detailed sectors, the chemicals sector has the smallest resiliency under water disruption (0.3478). Under gas disruptions, the other public services sector has the smallest value $(0.5500)$.

Water consumption in the chemicals sector is mainly attributed to cooling machines and products (34/51 firms), as well as raw materials (27/51 firms). The slight resiliency factor indicates water for these usages can be critical in the production process. Unfortunately, the reason why the other public service sector has the smallest resiliency factor is unclear partly because the sample size is too small and the standard deviation of resiliency factor is relatively large.

\footnotetext{
${ }^{6}$ However, there is a slight difference. In the manufacturing sector, the mitigation measures, which last for a long period, such as power generators for daily use, underground water, and propane gas, are considered. On the other hand, in the non-manufacturing sector, all mitigation measures are also considered.
} 
Table 2. Estimated Resiliency Factors (Manufacturing Sector, standard deviation is given in parentheses)

\begin{tabular}{|l|c|c|c|c|}
\hline \multicolumn{1}{|c|}{ Sector } & Electricity & Water & Gas & Sample Size \\
\hline Food & $0.03(0.02)$ & $0.38(0.05)$ & $0.68(0.05)$ & 69 \\
\hline Apparel \& Textile & $0.08(0.03)$ & $0.67(0.06)$ & $0.84(0.05)$ & 44 \\
\hline Wood \& Wooden Products & $0.08(0.05)$ & $0.75(0.08)$ & $0.89(0.06)$ & 20 \\
\hline Glass Stone Clay & $0.06(0.03)$ & $0.45(0.06)$ & $0.63(0.07)$ & 42 \\
\hline Paper-Pulp & $0.02(0.02)$ & $0.57(0.10)$ & $0.85(0.08)$ & 22 \\
\hline Chemicals & $0.08(0.03)$ & $0.36(0.06)$ & $0.76(0.05)$ & 51 \\
\hline Refinery \& Coal & $0.15(0.08)$ & $0.59(0.11)$ & $0.95(0.04)$ & 18 \\
\hline Metal Products & $0.04(0.02)$ & $0.59(0.04)$ & $0.76(0.04)$ & 89 \\
\hline Steel & $0.01(0.01)$ & $0.50(0.09)$ & $0.73(0.08)$ & 20 \\
\hline Non-Ferrous & $0.04(0.04)$ & $0.39(0.08)$ & $0.72(0.08)$ & 27 \\
\hline General Machinery & $0.07(0.03)$ & $0.64(0.06)$ & $0.84(0.05)$ & 34 \\
\hline Precision Machinery & $0.03(0.02)$ & $0.56(0.09)$ & $0.93(0.06)$ & 20 \\
\hline Elec. \& Electron & $0.08(0.03)$ & $0.71(0.05)$ & $0.90(0.04)$ & 43 \\
\hline Transport Eq & $0.03(0.01)$ & $0.51(0.05)$ & $0.64(0.05)$ & 70 \\
\hline Misc. Manufact & $0.08(0.02)$ & $0.51(0.04)$ & $0.75(0.04)$ & 86 \\
\hline Total Businesses & $0.06(0.01)$ & $0.53(0.02)$ & $0.76(0.03)$ & 655 \\
\hline
\end{tabular}

Table 3. Estimated Resiliency Factors (Non-Manufacturing Sector, standard deviation is given in parentheses)

\begin{tabular}{|l|c|c|c|c|}
\hline \multicolumn{1}{|c|}{ Sector } & Electricity & Water & Gas & Sample Size \\
\hline Construction & $0.29(0.07)$ & $0.63(0.07)$ & $0.86(0.07)$ & 21 \\
\hline Wholesale \& Retail & $0.31(0.04)$ & $0.51(0.05)$ & $0.67(0.05)$ & 59 \\
\hline Financial \& Insurance & $0.45(0.08)$ & $0.76(0.06)$ & $0.78(0.07)$ & 24 \\
\hline Real Estate & $0.39(0.07)$ & $0.48(0.07)$ & $0.64(0.08)$ & 20 \\
\hline Transportation & $0.37(0.07)$ & $0.67(0.06)$ & $0.73(0.08)$ & 27 \\
\hline Communication & $0.45(0.11)$ & $0.63(0.09)$ & $0.68(0.11)$ & 15 \\
\hline Medical Serv. & $0.40(0.05)$ & $0.51(0.05)$ & $0.66(0.06)$ & 46 \\
\hline Other Public Serv. & $0.60(0.13)$ & $0.65(0.13)$ & $0.55(0.18)$ & 5 \\
\hline Business Serv. & $0.26(0.07)$ & $0.76(0.07)$ & $0.90(0.06)$ & 22 \\
\hline Personal Serv. & $0.31(0.08)$ & $0.52(0.05)$ & $0.71(0.09)$ & 22 \\
\hline Agriculture, etc. & $0.52(0.12)$ & $0.65(0.10)$ & $0.63(0.12)$ & 12 \\
\hline Mining & $0.75(-)$ & $0(-)$ & $1(-)$ & 1 \\
\hline Total Businesses & $0.37(0.02)$ & $0.59(0.02)$ & $0.71(0.02)$ & 274 \\
\hline
\end{tabular}


To compare the resiliency factors between Japan and the US, the resiliency factors provided in ATC-25 are listed in Table 4. In both studies the order of resiliency factors among the three lifelines for the manufacturing and non-manufacturing sector is consistent. In other words, both manufacturing and non-manufacturing sectors have the greatest resilience against gas disruption, followed by water disruption; both sectors have the least resilience against electricity disruption. In addition, the average values of the resiliency factors for the non-manufacturing sector are relatively larger. However, when a detailed comparison is made, it is difficult to discover a consistent relationship.

Note that the resiliency factors in both the studies involve different survey and estimation methods. Estimation in ATC-25 is based on expert opinions (which are limited in quantity), whereas the current study utilized questionnaire surveys. Questionnaire surveys take advantages of the evaluation of statistical characteristics of resilience in large samples.

Table 4. Resiliency factors in the U.S. (ATC-25)

\begin{tabular}{|l|l|l|l|l|l|l|l|}
\hline Manufacturing sector & E & W & G & $\begin{array}{l}\text { Non-Manufacturing } \\
\text { sector }\end{array}$ & E & W & G \\
\hline \hline Food Tobacco & 0.1 & 0.3 & 0.75 & Construction & 0.6 & 0.5 & 1 \\
\hline Textile Goods & 0 & 0.3 & 0.8 & Wholesale Trade & 0.1 & 0.8 & 0.9 \\
\hline Lumber \& Wood & 0 & 0.5 & 0.8 & Retail Trade & 0.1 & 0.8 & 0.8 \\
\hline Glass Stone Clay & 0 & 0.5 & 0.5 & F.I.R.E c $^{\text {c }}$ & 0.1 & 0.8 & 0.8 \\
\hline Pulp \& Paper & 0 & 0.4 & 0.6 & Transp \& Whse & 0.7 & 0.8 & 1 \\
\hline Chemical \& drugs & 0.1 & 0.2 & 0.1 & Health Ed Soc. & 0.2 & 0.6 & 0.8 \\
\hline Petrol. Refining & 0 & 0.5 & 0.5 & Govt \& Govt Ind. & 0.4 & 0.75 & 0.8 \\
\hline Prim. Metal Prd & 0.1 & 0.1 & 0.5 & Pers./Prf Serv. & 0.1 & 0.8 & 0.8 \\
\hline Fab. Metal Prod & 0 & 0.2 & 0.5 & Agriculture, etc d). & 0.5 & 0.467 & 0.77 \\
\hline Mach. Exc. Elec & 0 & 0.4 & 0.5 & Mining & 0.1 & 0.85 & 0.9 \\
\hline Elec. \& Electron & 0 & 0.1 & 0.5 & & & & \\
\hline Transport Eq & 0 & 0.4 & 0.5 & & & & \\
\hline Misc. Manufact & 0 & 0.4 & 0.5 & & & & \\
\hline \hline Average & 0.02 & 0.36 & 0.58 & Average & 0.29 & 0.72 & 0.86 \\
\hline Average (Tokai) & 0.06 & 0.54 & 0.79 & Average (Tokai) & 0.42 & 0.56 & 0.73 \\
\hline
\end{tabular}

c) Finance, Insurance and Real Estate

d) Average of Live stock, Agr. Prod., and AgServ For Fish. 


\section{ESTIMATION OF RESILIENCY FACTOR ASSUMING MULTIPLE LIFELINE DISRUPTIONS AND RESILIENCY OPTIONS}

In the previous section, we evaluated resiliency factor as the average of production levels of individual businesses under individual lifeline disruptions (i.e., reflecting only individual lifeline importance factor). This section aims to investigate some more factors that influence business resilience, which are discussed in Section 2. One factor is multiple lifeline disruption scenarios in Figure 1, which is the most likely case during an earthquake disaster. By estimating resiliency factor under different patterns of lifeline disruptions, it is possible to capture the business impacts according to different recovery scenarios.

Then, the effects of several resiliency options are discussed to understand the importance of considering these options not only for individual business but also for local governments who conduct loss estimation during a disaster. We considered two types of resiliency options-backups and alternative lifeline resources. These options mainly include (backup) power generators, water storage and underground water, etc. The second option includes all the options that are related to the timing of production. Production rescheduling and use of inventories are representative options, and these are reflected in tolerable disruption duration. Finally, we estimate the resiliency factor under the lifeline disruption scenarios during the Tokai Earthquake to represent the total business resilience under likely lifeline disruption scenarios.

\section{INTERACTION EFFECTS OF SIMULTANEOUS LIFELINE DISRUPTIONS}

Chang et al. (1996) studied the individual and simultaneous economic impacts of electricity, water, and gas disruptions. In order to assess the impact of simultaneous 
disruptions, they "assumed that a particular industry (for the specific day and census tract) would suffer direct economic loss equal to the greatest of the losses from the three lifelines individually." However, it is also pointed out that this assumption may lead to underestimates of the economic loss from multiple lifeline disruption.

The input-output model is also one of the most popular methods for evaluating economic losses during periods of lifeline disruption. The input-output model uses the Leontief-type production function, which assumes that different inputs are not substitutable for production. Under this assumption, based on available information of the average input of lifelines for the production activities of each sector, economic losses are calculated linearly with the loss of lifelines. However, in a normal case, inputs and outputs do not follow the Leontief-type production function, because there are interaction effects, such as a substitution relationship among lifelines.

To overcome the disadvantages of the input-output model, CGE (computable general equilibrium) model is adopted in the recent research on economic impacts estimation (e.g. Rose and Liao (2005), Tsuchiya et al. (2007)). CGE modeling does allow for substitution possibilities and is thus better suited than input-output analysis at addressing the issue of multiple lifeline failures. However, the number of empirical studies that provide parameters of production functions are limited.

Interaction effects of different lifeline disruption patterns were partly observed in past disasters. For example, increasing the capacity of a gas-powered generator corresponds to a substitution relationship. In addition, during water lifeline (both drinking and industrial use) disruptions, more underground water can be used than usual. In a single lifeline disruption case, these types of interaction effects are well reflected by considering the following 
examples: city gas is available during electricity disruption and underground water is available using electric pumps.

Therefore, usage of multiple lifeline cannot simply be classified as a Leontief-type linear relationship; further, multiple lifeline disruptions are more severe than individual lifeline disruptions. Hence, resiliency factors under simultaneous lifeline disruptions are also estimated based on a questionnaire survey and the results are presented in Tables 5 and 6 . Resiliency factors become smaller as the disruption patterns become more severe. In the manufacturing sector, the resiliency factor is almost zero if only the electricity disruption event is included, while non-manufacturing sectors retain some level of production under all lifeline disruptions.

Table 5. Resiliency factors under simultaneous disruptions for the manufacturing sector (E: electricity disruption, W: water disruption, G: gas disruption)

\begin{tabular}{|l|l|l|l|l|l|l|l|l|}
\hline Sector & E & W & G & WG & EG & EW & EWG & N \\
\hline Food & 0.04 & 0.46 & 0.65 & 0.40 & 0.02 & 0.01 & 0.00 & 43 \\
\hline Apparel \& Textile & 0.09 & 0.71 & 0.84 & 0.71 & 0.09 & 0.09 & 0.07 & 26 \\
\hline $\begin{array}{l}\text { Wood \& Wooden } \\
\text { Products }\end{array}$ & 0.06 & 0.91 & 1.00 & 0.91 & 0.06 & 0.06 & 0.06 & 8 \\
\hline Glass Stone Clay & 0.04 & 0.41 & 0.57 & 0.31 & 0.03 & 0.03 & 0.02 & 24 \\
\hline Paper-Pulp & 0.03 & 0.59 & 0.80 & 0.59 & 0.02 & 0.02 & 0.02 & 16 \\
\hline Chemicals & 0.05 & 0.34 & 0.76 & 0.31 & 0.03 & 0.03 & 0.02 & 33 \\
\hline Refinery \& Coal & 0.18 & 0.70 & 1.00 & 0.70 & 0.18 & 0.00 & 0.00 & 11 \\
\hline Metal Products & 0.01 & 0.64 & 0.78 & 0.61 & 0.01 & 0.01 & 0.01 & 53 \\
\hline Steel & 0.00 & 0.50 & 0.70 & 0.41 & 0.00 & 0.00 & 0.00 & 14 \\
\hline Non-Ferrous & 0.06 & 0.42 & 0.75 & 0.39 & 0.06 & 0.06 & 0.06 & 16 \\
\hline General Machinery & 0.01 & 0.64 & 0.92 & 0.64 & 0.00 & 0.00 & 0.00 & 20 \\
\hline Precision Machinery & 0.02 & 0.71 & 0.91 & 0.68 & 0.00 & 0.00 & 0.00 & 11 \\
\hline Elec. \& Electron & 0.07 & 0.74 & 0.89 & 0.71 & 0.03 & 0.04 & 0.04 & 34 \\
\hline Transport Eq & 0.02 & 0.52 & 0.59 & 0.42 & 0.02 & 0.02 & 0.01 & 45 \\
\hline Misc. Manufact & 0.08 & 0.47 & 0.66 & 0.40 & 0.05 & 0.07 & 0.04 & 57 \\
\hline Total & 0.05 & 0.55 & 0.74 & 0.51 & 0.04 & 0.03 & 0.02 & 411 \\
\hline
\end{tabular}


Table 6. Resiliency factors under simultaneous disruptions for the non-manufacturing sector (E: electricity disruption, $\mathrm{W}$ : water disruption, G: gas disruption)

\begin{tabular}{|l|l|l|l|l|l|l|l|l|}
\hline & $\mathrm{E}$ & $\mathrm{W}$ & $\mathrm{G}$ & $\mathrm{WG}$ & $\mathrm{EG}$ & $\mathrm{EW}$ & EWG & Sample Size \\
\hline Construction & 0.29 & 0.69 & 0.88 & 0.67 & 0.27 & 0.23 & 0.15 & 12 \\
\hline Wholesale-Retail & 0.21 & 0.58 & 0.76 & 0.57 & 0.22 & 0.20 & 0.14 & 25 \\
\hline Financial-Insurance & 0.41 & 0.80 & 0.85 & 0.75 & 0.33 & 0.31 & 0.24 & 20 \\
\hline Real Estate & 0.44 & 0.60 & 0.71 & 0.60 & 0.44 & 0.40 & 0.21 & 13 \\
\hline Transportation & 0.27 & 0.77 & 0.91 & 0.68 & 0.23 & 0.21 & 0.14 & 14 \\
\hline Communication & 0.25 & 0.84 & 0.97 & 0.84 & 0.19 & 0.19 & 0.13 & 8 \\
\hline Medical Serv. & 0.32 & 0.52 & 0.71 & 0.43 & 0.20 & 0.19 & 0.12 & 24 \\
\hline Other Public Serv. & 0.25 & 0.75 & 0.75 & 0.50 & 0.25 & 0.25 & 0.25 & 1 \\
\hline Business Serv. & 0.26 & 0.78 & 0.87 & 0.77 & 0.22 & 0.18 & 0.16 & 17 \\
\hline Personal Serv. & 0.20 & 0.50 & 0.85 & 0.45 & 0.20 & 0.15 & 0.10 & 10 \\
\hline Agriculture, et al. & 0.25 & 0.71 & 0.83 & 0.67 & 0.29 & 0.25 & 0.13 & 6 \\
\hline Mining & 0.75 & 0.00 & 1.00 & 0.00 & 1.00 & 1.00 & 0.00 & 1 \\
\hline Total & 0.30 & 0.66 & 0.82 & 0.62 & 0.26 & 0.24 & 0.15 & 151 \\
\hline
\end{tabular}

When all lifelines get disrupted, recovery of electricity is most effective, followed by water when it comes to enhancing production levels. Recovery of gas is more effective once the electricity and water supplies have been recovered. However, in an electricity disruption, recovery of both water and gas is equally important.

\section{EFFECTS OF BACK-UP AND ALTERNATIVE LIFELINE RESOURCES}

Resiliency factors are not determined only by the lifeline-use characteristics of sectors, but also by the resiliency options of each business, such as installation of back-up systems. As is discussed in the previous section, in our survey on the non-manufacturing sector, we solicited two production levels under lifeline disruption: with and without considering effects of resiliency options, in order to explicitly estimate the contributions of these options to resiliency factors. 
Resiliency options in this study are mostly related to backup systems and alternative resources. Backup power generators are considered to be the major resiliency option against electricity disruption ${ }^{7}$. The introduction rates of power generators for either daily or backup use are greatest in the financial \& insurance $(0.33)$ and the medical services industries $(0.36)$. With regard to the resiliency options against water disruption, the use of underground water, river water, lake water, and water storage facilities is prominent. The number of resiliency options per business is large in agriculture, etc. (0.77), and is followed by the medical services industry (0.62). The main countermeasure against gas disruption is the introduction of propane gas ${ }^{8}$.

In the nonmanufacturing sector, the effect of each resiliency option on resiliency factors under electricity and water disruption is obtained by subtracting the resiliency factors without resiliency options from the resiliency factors when resiliency options are considered; the results are shown in Table 7. The sample size for the nonmanufacturing sector is relatively small as compared to the total sample size of the nonmanufacturing sector. This is because firms having more than two options are excluded; moreover, firms that replied both the options-with and without resiliency options-are limited. The number of firms with resiliency options are as follows: power generators: 47 (introduction rate $=0.132$ ), underground water: $86(0.24)$, river \& lake: $26(0.10)$, water storage: $65(0.18)$.

\footnotetext{
${ }^{7}$ There are many types of resources for backup generators-for instance, solar energy, diesel, natural gas, etc. The availability of these resources during a disaster may vary; however, this study does not consider and classify these differences.

${ }^{8}$ The major countermeasure against gas lifeline disruption is the use of propane gas. However, most firms in the nonmanufacturing sector did not consider and compare the cases where propane gas was available or unavailable.
} 
Table 7. Effects of individual resiliency options in the nonmanufacturing sector

\begin{tabular}{|l|c|c|c|c|}
\hline $\begin{array}{l}\text { Resiliency } \\
\text { options }\end{array}$ & $\begin{array}{l}\text { Average \% covered by } \\
\text { options (in terms of daily } \\
\text { usage) }\end{array}$ & $\begin{array}{l}\text { Resiliency factor } \\
\text { (without options) }\end{array}$ & $\begin{array}{l}\text { Resiliency factor } \\
\text { (with options) }\end{array}$ & $\begin{array}{l}\text { Sample } \\
\text { size }\end{array}$ \\
\hline $\begin{array}{l}\text { Power } \\
\text { generators }\end{array}$ & $36 \%$ & 0.25 & 0.61 & 24 \\
\hline $\begin{array}{l}\text { Underground } \\
\text { water }\end{array}$ & $72 \%$ & 0.44 & 0.67 & 9 \\
\hline River, lake & - & 0.53 & 0.58 & 9 \\
\hline Water storage & - & 0.50 & 0.59 & 19 \\
\hline
\end{tabular}

In Table 7, the effects of the resiliency options are clearly shown, especially for power generators and underground water. However, it is necessary to obtain more data sets and analyze the effects of the size and scale of backups and alternative resources in order to generalize this result. In the detailed analysis, all the samples are used regardless of which of the two resiliency factors the firm has replied with.

In this case, the effects of back-ups or alternative power generators are remarkable in the financial \& insurance (resiliency factor increased by an average of 0.156 ), agriculture, etc. (0.096), and medical services (0.086) industries. The large introduction rates of backup generators are reflected in the financial \& insurance and medical services industries. On the other hand, fewer changes are observed among firms with or without resiliency options against water disruption.

\section{ACCEPTABLE DURATION OF PRODUCTION STOPPAGE}

When businesses know the restoration period of a lifeline, they can recover their temporary losses using inventories or the full capability of their production systems, as shown in Figure 2. Table 8 presents the average number of days acceptable for production stoppage without economic loss. This is estimated by subjective answers based on inventory 
amounts, the hours per day spent running the production system, and production scheduling from order to delivery. Relationships between customers and clients are implicitly and subjectively considered. Because complete production stoppages mainly occur in the manufacturing sector due to electricity disruption, for this situation, the estimated values correspond to $t^{\prime}$ in Equation (4). $t$ ' can be larger in cases where production partly continues vis-à-vis cases where production ceases completely.

Table 8 presents the obtained results. In contrast to the resiliency factor in terms of the production levels in Tables 2 and 3, nonmanufacturing businesses such as transportation (1.84), communication (2.55), financial \& insurance services (2.68), and medical services (2.85) are relatively less resilient as compared to businesses in the manufacturing sector. In the manufacturing sector, food (3.03) and transport eq. (3.22) have little resilience.

Table 8. Acceptable days of production stoppage

\begin{tabular}{|l|l|l|l|}
\hline Manufacturing & Days & Nonmanufacturing & Days \\
\hline Food & 3.03 & Construction & 4.31 \\
\hline Apparel \& Textile & 6.43 & Wholesale \& Retail & 3.42 \\
\hline Wood \& Wooden Products 10.15 & Financial \& Insurance & 2.68 \\
\hline Glass Stone Clay & 11.59 & Real Estate & 9.09 \\
\hline Paper Pulp & 6.09 & Transportation & 1.84 \\
\hline Chemicals & 7.00 & Communication & 2.55 \\
\hline Refinery \& Coal & 4.60 & Medical Serv. & 2.85 \\
\hline Metal Products & 5.82 & Other Public Serv. & 7.25 \\
\hline Steel & 5.82 & Business Serv. & 6.24 \\
\hline Nonferrous & 3.75 & Personal Serv. & 3.28 \\
\hline General Machinery & 8.02 & Agriculture, etc. & 3.71 \\
\hline Precision Machinery & 8.15 & Mining & 3.50 \\
\hline Elec. \& Electron & 5.86 & & \\
\cline { 1 - 2 } Transport Eq & 3.22 & & \\
\hline Misc. Manufact & 6.30 & & 4.23 \\
\hline Average & 6.39 & Average &
\end{tabular}




\section{RESILIENCY FACTORS UNDER THE SCENARIO OF LIFELINE DISRUPTIONS CAUSED BY THE TOKAI EARTHQUAKE}

The previous subsections investigated the individual factors of business resilience. This subsection integrates all the factors of resilience depicted in Figure 1 and estimates the resiliency factor based on Equation (4). As a case study, the scenario of lifeline disruptions caused by the Tokai Earthquake is singled out. In Shizuoka prefecture, it is estimated that the worst area suffers 6-12 days of electricity disruptions and 30 days of water and gas disruptions. Because the restoration periods of each lifeline in Aichi prefecture are unavailable, this study estimates the resiliency factor for a worst-case scenario in the Shizuoka prefecture.

Figure 8 shows the estimation results under the assumption that all the businesses suffer 12 days of electricity disruption and 30 days of water and gas disruptions. We use the GRP (gross regional product) of Shizuoka prefecture for the year 2005 (Shizuoka prefecture (2007)) and assume that one-twelfth of the GRP is produced during the 30 days evaluation period. Some of the sectors are integrated as per the classification rules of Shizuoka prefecture (2007). Tables 5 and 6 are adopted to estimate the production level under multiple lifeline disruptions, and Table 8 is applied to estimate the temporal production adjustments such as recovery of production at a later date.

In Figure 8 , the total value of estimated losses is 828,155 million yen. The resiliency factor for the entire prefecture is 0.44 , where 0.38 is produced by maintaining production under lifeline disruptions and 0.06 is produced by temporal production adjustments. The Food and Transport Eq. industries have the lowest resiliency -0.30 and 0.31 , respectively. This is because the dependence on lifelines is large and the acceptable production stoppage duration is short. 


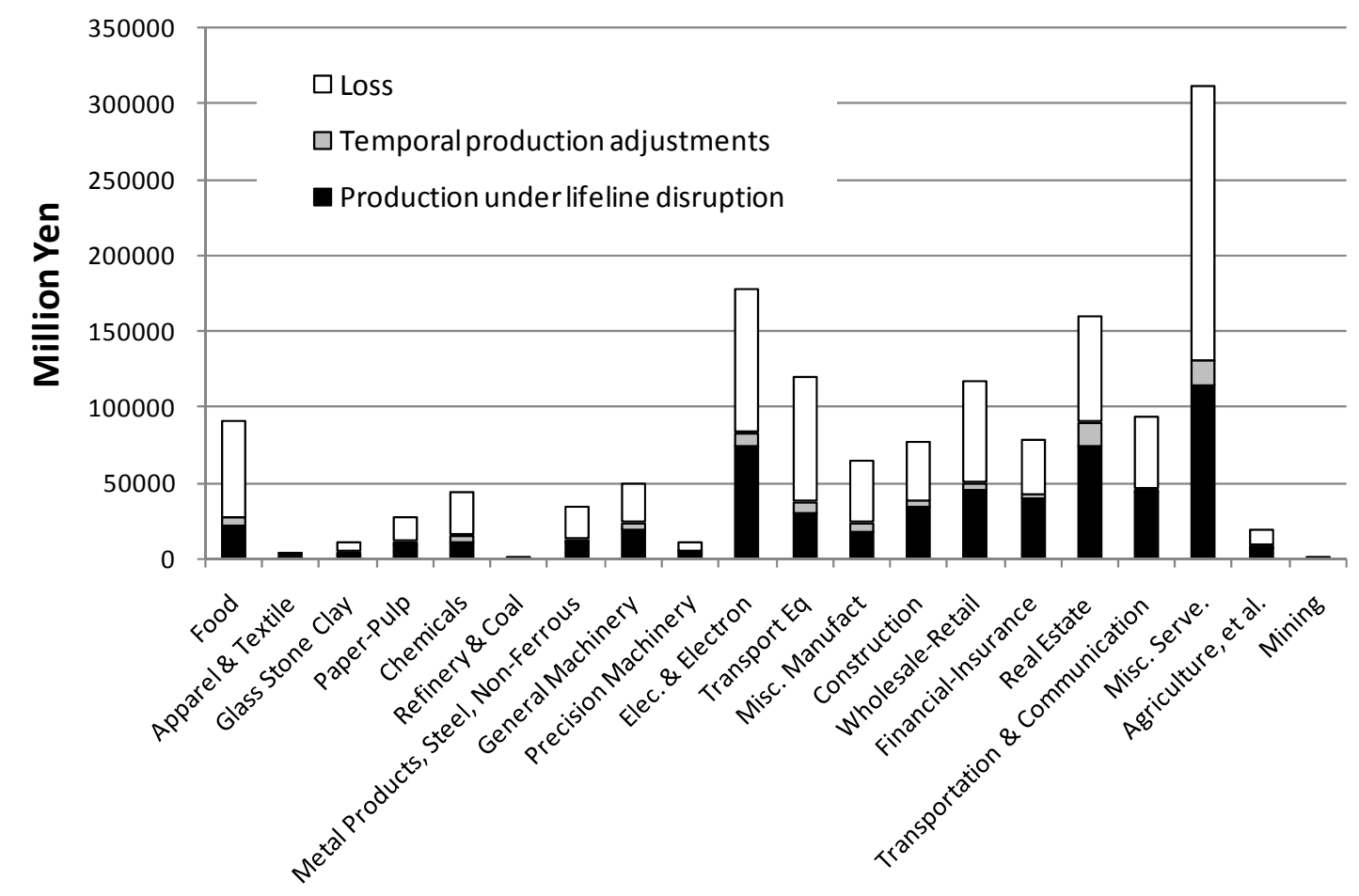

Figure 8. Resiliency and Loss estimation results under the scenario of lifeline disruptions during the Tokai earthquake. All the businesses are assumed to suffer 12 days of electricity disruptions and 30 days of water and gas disruptions.

\section{CONCLUSIONS}

This study focuses on resiliency factors under lifeline disruptions (electricity, water, and gas) and reports on a survey conducted in the Tokai area (Aichi and Shizuoka prefectures), Japan. An index was originally developed in ATC-13 (1985), which played an important role in estimating economic losses caused by lifeline disruptions. Our main purpose in this study is to develop resiliency factors (importance factors) for Japanese industries; the resiliency factors for 27 sectors are obtained based on a questionnaire, which accumulated 655 effective replies from companies in the manufacturing sector and 274 effective replies from those in 
the nonmanufacturing sector. The resiliency factors given in ATC and those obtained from our study are consistent to some degree when one considers the entire sample from the manufacturing and nonmanufacturing sectors. However, the results are not as consistent in the detailed sectors.

In addition, this study points out that the concept of resiliency factors has been theoretically extended by many researchers; however, resiliency factors have not been fully investigated on the basis of real field data. Therefore, this study focuses on important topics related to resiliency factors that have not been examined, such as the effects of resiliency options and simultaneous lifeline disruptions. Backups and alternative resources and temporal production adjustment, such as production recovery at a later date, are considered to be resiliency options. These matters are also discussed on the basis of the surveyed data; the findings are outlined below.

By considering multiple lifeline disruptions, the production level corresponding to lifeline disruptions and recovery patterns can be calculated. In the manufacturing sector, the resiliency factor is almost zero if only the electricity supply is disrupted. In cases where electricity is supplied, water becomes more important in terms of recovering production levels faster. In the nonmanufacturing sector, water and gas supplies have more importance even when the electricity supply is disrupted.

With regard to resiliency options in the nonmanufacturing sector, the effects of each option are clearly reflected in the resiliency factors. In other words, the samples with resiliency options tend to have larger resiliency factors. In the sectoral analysis, we found that publicly important sectors such as financial \& insurance and medical services are well prepared for lifeline disruptions; this is reflected in their respective resiliency factors. In all the firms surveyed, a few days of production stoppage does not directly relate to economic 
loss. Businesses can tolerate or recover the temporary loss by production stoppages. These resiliency characteristics tend to be the highest in the manufacturing sector.

In this manner, several characteristics of resiliency factors have been quantitatively and empirically investigated. Further, our case study on the Tokai earthquake in Japan shows that the business sectors had less resilience under the assumed lifeline disruption scenarios. More investigations, such as an analysis based on the data sets in a small spatial scale, are necessary to obtain more plausible estimation results. However, our basic empirical estimation results can be applied to find the effects of countermeasures on lifeline systems as well as to find the effects of installing new resiliency options in each business.

\section{REFERENCES}

Applied Technology Council (ATC), 1985. Earthquake Damage Evaluation Data for California, ATC-13, Redwood City, CA.

Applied Technology Council (ATC), 1991. Seismic Vulnerability and Impact of Disruption of Lifelines in the Conterminous United States, ATC-25, Redwood City, CA.

Bruneau, M., Chang, S.E., Eguchi, R.T., Lee, G.C., O’Rouke, T.D., Reinhorn, A.M., Shinozuka, M., Tierney, K., Wallace, W.A., and von Winterfeldt, D., 2003. A framework to quantitatively assess and enhance the seismic resilience of communities, Earthquake Spectra 19, 4, 733-752.

Chang, S.E., Seligson, H., and Eguchi, R., 1996. Estimation of economic impact of multiple lifeline disruption: Memphis light, gas, and water division case study, Technical Report No. NCEER96-0011. Multidisciplinary Center for Earthquake Engineering Research, Buffalo, NY.

Chang, S. E., 1998. Direct Economic Impacts, Chapter 6 in Engineering and Socioeconomic Impacts of Earthquakes (Shinozuka M, Rose A, Eguchi R. eds.), Multidisciplinary Center for Earthquake Engineering Research, Buffalo, NY.

Chang, S.E., Svekla, W.D., and Shinozuka, M., 2002. Linking infrastructure and urban economy: Simulation of water disruption impacts in earthquakes, Environ. Plan. B: Plan. Des. 29, 2, 281-301. 
Chang, S. E. and Shinozuka, M., 2004. Measuring improvements in the disaster resilience of communities, Earthquake Spectra 20, 3, 739-755.

Federal Emergency Management Agency (FEMA), 2007. HAZUS-MH. Washington, DC.

Kajitani, Y., Tatano, H., Yamano, N., and Shumuta, Y., 2005. Estimation of resiliency factor of manufacturing sector under multiple lifeline disruptions, Journal of Natural Disaster Science 23, 4, 553-564.

Kajitani, Y., Tatano, H., Yamano, N., and Shumuta, Y., 2005. Estimation of resiliency factor of non-manufacturing sector under multiple lifeline disruptions, Journal of Natural Disaster Science 24, 3, 247-255.

Risk Management Solutions, Inc., 1995. What If the 1923 Earthquake Strikes, Again? A FivePrefecture Tokyo Region Scenario, Topical Issues Series, Menlo Park, CA.

Rose, A., 2004. Defining and measuring economic resilience to disasters, Disaster Prevention and Management 13, 307-14.

Rose, A., Benavides, J., Chang, S., Szczesniak, P., and Lim, D., 1997. The regional economic impact of an earthquake: direct and indirect effects of electricity utility damages, Journal of Regional Science 37, 3, 437-458.

Rose, A. and Liao, S., 2005. Modeling regional economic resilience to disasters: A computable general equilibrium analysis of water service disruptions, Journal of Regional Science 45, 1, 75-112.

Rose, A. and Lim, D., 2002. Business interruption losses from natural hazards: Conceptual and methodology issues in the case of the Northridge Earthquake, Environmental Hazards: Human and Social Dimensions 4, 1-14.

Rose, A., Oladosu, G., and Liao, S., 2007. Regional economic impacts of a terrorist attack on the water system of Los Angeles: A computable general disequilibrium analysis, Risk Analysis 27, 3, 513-531.

Shizuoka Prefectural Earthquake Preparedness Education Center, 2007. The third damage estimation by the Tokai Earthquake, http://www.e-quakes.pref.shizuoka.jp/data/higai/3gaiyou.htm.

Shizuoka Prefecture, 2007. 2005 Prefectural economic accounting, http://toukei.pref.shizuoka.jp/tokei/sz0010.asp?kbn=11

Tsuchiya, S., Tatano, H., and Okada, N., 2007. Economic loss assessment due to railroad and highway disruptions, Economic Systems Research 19, 2, 147-162. 


\section{APPENDIX A SURVEY FORMS FOR KEY QUESTIONS}

\section{Question I}

Assume that your company faces disruptions in electricity (from power companies), water (for public and industrial use), and city gas. In each case, please reply the level of production activity in your company. If the countermeasures are permanently available, please consider the effects of countermeasures. (e.g. Company A has installed water pumps. If electricity is supplied, company A can maintain production level 50\%. Company $\mathrm{B}$ can maintain normal production level through generator back-ups during electricity disruptions.) In this case, other problems for production such as damages to traffic and employees are not considered.

(In non-manufacturing case, this question is divided into two different questions: with and without resiliency options)

Please select one from the following 5 production levels under each lifeline disruption pattern (compared to normal), or fill in the more appropriate number in the 6. ( ).

\begin{tabular}{|l|l|l|l|l|l|l|}
\hline E & W & G & W,G & E,G & E,W & E,W,G \\
\hline 1. stop & 1. stop & 1. stop & 1. stop & 1. stop & 1. stop & 1. stop \\
2. (about) $25 \%$ & $2.25 \%$ & $2.25 \%$ & $2.25 \%$ & $2.25 \%$ & $2.25 \%$ & $2.25 \%$ \\
$3.50 \%$ & $3.50 \%$ & $3.50 \%$ & $3.50 \%$ & $3.50 \%$ & $3.50 \%$ & $3.50 \%$ \\
$4.75 \%$ & $4.75 \%$ & $4.75 \%$ & $4.75 \%$ & $4.75 \%$ & $4.75 \%$ & $4.75 \%$ \\
$5.100 \%$ & $5.100 \%$ & $5.100 \%$ & $5.100 \%$ & $5.100 \%$ & $5.100 \%$ & $5.100 \%$ \\
$6 .(\quad) \%$ & $6 .(\quad \%$ & $6 .(\quad) \%$ & $6 .(\quad) \%$ & $6 .(\quad) \%$ & $6 .(\quad) \%$ & $6 .(\quad) \%$ \\
\hline
\end{tabular}

E: (disruption of) Electricity W: Water G: Gas

Question II

Please reply the tolerable production stoppage periods, which indicates no economic loss is generated during the periods (such as the losses due to the cancellation of orders).

1. 1 day; $2.2-3$ days; 3.5 days; 4.1 week; 5.10 days; 6.2 weeks; 7. 20 days; 8.1 month; 9. Over 1 month ( )

Kajitani -32 